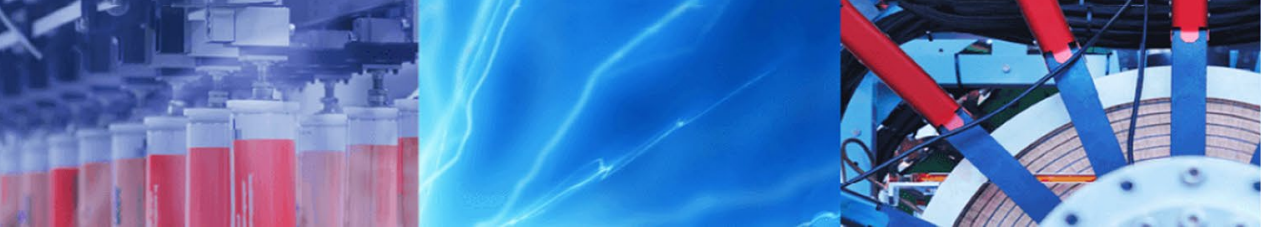

Research Article

\title{
Spatiotemporal patterns of surface temperature over western Odisha and eastern Chhattisgarh
}

\author{
Keval Maniar ${ }^{1} \cdot$ Sandeep Pattnaik ${ }^{1}$ D
}

(c) Springer Nature Switzerland AG 2019

\begin{abstract}
Extreme temperature indices are a matter of serious concern to human as well as ecological activities. They are directly or indirectly affect the health, agriculture and socioeconomic progress. Regional-scale heat wave analysis is highly important for obtaining firsthand information about the impact of extreme temperature. This study examines the trends and variability in frequency, and intensity of warm/cold days/nights to assess the impact of climate change over ten districts of western Odisha and five districts of neighboring Chhattisgarh. Though this region is industrialized, its population is highly vulnerable socioeconomic conditions within India. This study examines daily maximum and minimum temperature during the summer months (i.e., March, April and May) for 30 years (i.e., 1988-2017) over this region, using the ERA-Interim data sets at horizontal resolution of $12 \mathrm{~km}$. Results suggest that the daily maximum, minimum and mean temperature over the study region increase at the rate of $0.006^{\circ} \mathrm{C}, 0.012^{\circ} \mathrm{C}$ and $0.017^{\circ} \mathrm{C}$ per year, respectively. Alarmingly, frequency and intensity of warm night have increased, whereas frequency and intensity of cold nights have decreased over the years. Raigarh in Chhattisgarh has the highest increasing trend of warm night frequency (0.13 times/year) followed by Jharsuguda, Sundargarh and Sambalpur in Odisha. In addition, Sundargarh has the highest increasing trend of warm day (night) intensity 0.065 days/year ( 0.07 days/year) followed by Jharsuguda, Sambalpur, Raigarh and Janjgir Champa. The frequency of cold days in all districts shows negative trends with highest ( -0.06 times/year) in Sambalpur. Threeday trend values, highest over Sundargarh, for the warm (cold) nights are 0.05 days/year ( - 0.05 days/year). Evidently, numbers of warm nights have increased, and those of cold nights have decreased over this region.
\end{abstract}

Keywords Warm/cold day/night frequency $\cdot$ Intensity $\cdot$ Extreme temperature $\cdot$ Heat wave

\section{Introduction}

The Intergovernmental Panel on Climate Change (IPCC) assessment reports (IPCC, 2007) suggest that consequently occurring climate extremes are likely to increase the frequency and intensity in the future. The world has witnessed the major heat wave events in the recent past $[6,33,41]$, especially over densely populated urban areas across the globe including India, where most of the human population is vulnerable to the severe impacts of these heat wave events $[7,18,21,29,34]$. The tragic and severe heat wave events of India have occurred during 1998 and
2015 causing a massive loss of lives. In 1998 (2015), the total number of reported deaths was $1300(>2500)$, out of which 650 (35) deaths happened in Odisha [8, 34]. In addition, the heat wave events are one of the major factors for the climate migration of population around the globe, particularly over the rural areas [4].

The 1998 heat wave event is ranked among the most deadly events globally. In India, almost every year, heat waves mostly occurred during the pre-monsoon season (March, April, May months here onwards MAM) and cover major states of the country, causing high mortality and affecting a livelihood of large number of population and

Sandeep Pattnaik, spt@iitbbs.ac.in | ${ }^{1}$ School of Earth, Ocean and Climate Sciences, Indian Institute of Technology Bhubaneswar (IIT Bhubaneswar), Argul, Jatni, Khurda, Odisha 752 050, India.

SN Applied Sciences (2019) 1:991 | https://doi.org/10.1007/s42452-019-0986-2

Received: 11 April 2019 / Accepted: 25 July 2019 / Published online: 6 August 2019 
health hazards and agriculture [10, 27, 39, 22, 32]. In most parts of the Indian subcontinent, an increase in extreme temperatures is observed in terms of decreases in cold extremes and increases in warm extremes [28]. Previous studies show that North India suffers from the nighttime heat wave and South Indian temperature indices are mainly because of daytime temperature [28].

Pai et al. $[26,27]$ showed that in 1991-2000, there is a noticeable increase in the frequency of high-frequency temperature extreme events (i.e., heat waves). Further, these studies also indicated that there is an increase in the frequency and intensity of severe heat waves over Odisha. Srivastava et al. [40] have found that the annual frequency of hot days has an increasing trend (5.1 days/decade) over Odisha, and the daily maximum temperatures also increase significantly over Odisha. Analysis reveals that the mean temperature of the Odisha state has increased by $\sim 0.3{ }^{\circ} \mathrm{C}$ during the past three decades (1981-2010) with the most accelerated warming $\left(\sim 0.9^{\circ} \mathrm{C}\right)$ occurring during the recent decade (2001 to 2010). Interestingly 25 to $50 \%$ of observed overall warming is associated with land use/land cover [12]. Additionally, using Indian Meteorological Department (IMD) gridded data, Ross et al. [35] has noted that the decadal mean temperature from 1 April to 31 May over India has increased by $1^{\circ} \mathrm{C}$ in the 2010 s compared to the 1950 s; in addition, annual mean temperature trend over western Odisha and Chhattisgarh region is $1.5^{\circ} \mathrm{C} / 100$ year over the period for 1901-2016. These are the major factors for considering this particular area for carrying out this research study (Fig. 1). Coupled Model Intercomparison Project 5 (CMIP5) projections suggesting high-intensity heat waves of longer duration are projected to be more frequent over the Indian region [23]. The regional Global Climate Model (GCM) has predicted that the greater frequency of extremely warm days and lower frequency of extremely cold days are associated with a warmer mean climate; it also shows the decrease in diurnal temperature range just because of higher nighttime temperatures [20].

It is noted that the pronounced day and night time warming has been adversely impacting rice yield over India [31] and Odisha being one of the leading states in the country for the production of rice will be impacted. Further, kharif crops (sown in May to June and harvested in September to October) are more impacted than rabi crops owing to the variability in rainfall associated with heat wave (Heat action plan for Odisha, 2018). Akhtar [2] has shown that due to extreme temperature variability during daytime and nighttime, the rural and urban areas of Odisha, parts of Uttar Pradesh, Bihar, Rajasthan and Andhra Pradesh are major regions that are affected by heat waves almost every year, resulting in high human mortality (3023 deaths during 1999-2014). A shred of evidence from a study of disaster risk management program on the adaptation strategy for reducing mortality from heat waves revealed that the increase in the number of heat waves days is associated with the increase in causalities in Odisha which may be due to adaptive failure or physiological reasons [38].

Environmental temperature and land surface temperature (LST) are getting impacted due to changes in land use/land cover (LULC) [13]. Due to urbanization, there is a reduction in agricultural and rural LULC over Indian region facilitating an increase in mean LST over the region [5]. The western Odisha particularly Jharsuguda-Brajrajnagar-Belpahar industrial belt is emerging as an industrial hub of India [17]. These industries contribute immensely to the rise in temperature over the region and augment the heat wave condition. Study over Zonguldak (Turkey), using Landsat- 5 data, suggests that significant differences are
Fig. 1 Ten districts of western Odisha (blue) and five districts of eastern Chhattisgarh (green)

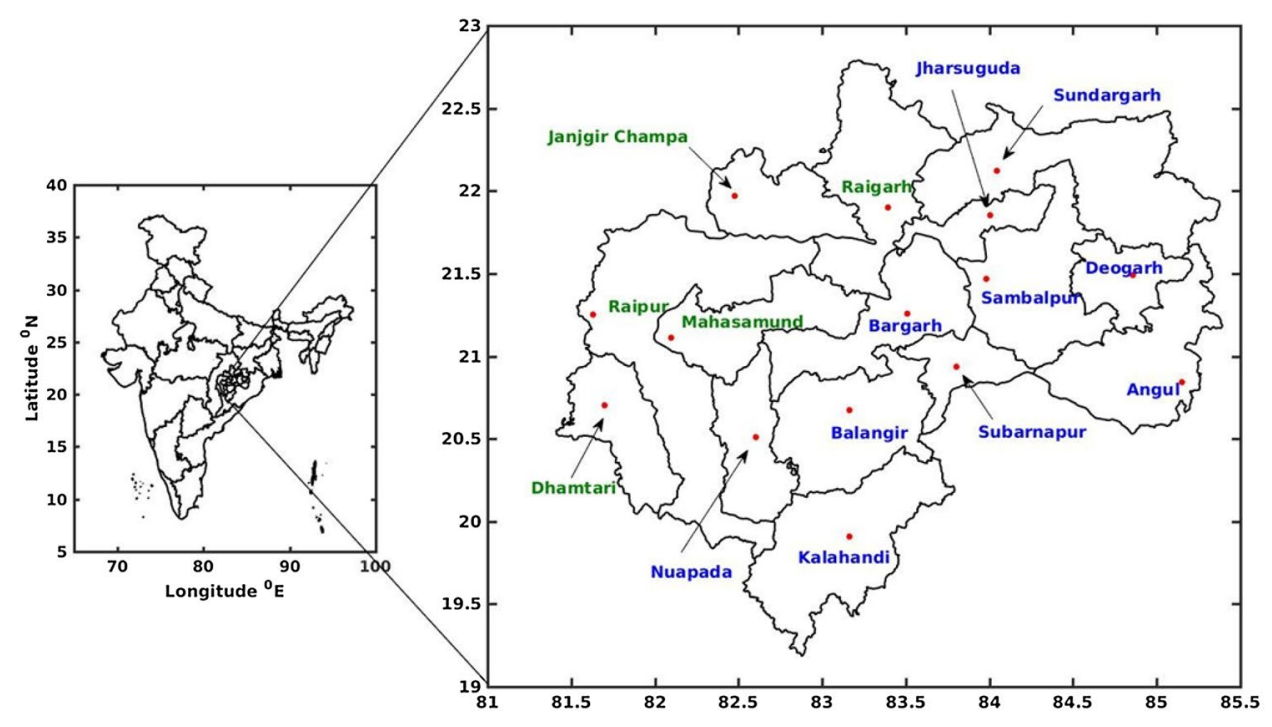


noted in the surface temperature (approx. $8^{\circ} \mathrm{C}$ ) between forestland and industrial land throughout the time period 1986-2015, implying the importance surface temperature variability based on different land types [36]. A comparative analysis done by Jena [16], on the impact of climate change on Odisha, suggested that the summers in Odisha state have become prolonged, winters have become warmer and rainy days have reduced from above 120 to 90 days. Further, the same study has suggested that about $70-75 \%$ of Odisha's population is in rural regions and mainly depends upon agriculture. The agricultural sector contribution in gross state domestic product (GSDP) has come down to 16 percent in 2011-2012 compared to 53 percent in 1980-1981.

Gouda et al. [12] using Weather Research and Forecasting (WRF) model found that temperature is above $47^{\circ} \mathrm{C}$ in places over western and central Odisha, while Titlagarh recorded the highest temperature of $50^{\circ} \mathrm{C}$ during the month of May 1998 . The positive $\left(0.04^{\circ} \mathrm{C} /\right.$ year $)$ trend of maximum temperature was found over Odisha during the period (1969-2015). Mean of the trends of the highest temperature of the year (1971-2015) over Eastern India (includes Odisha and Chhattisgarh) in the average of 22 CMIP5 ensemble models indicates positive trends between 0.02 and $0.03 \mathrm{~K} /$ year [25]. In our previous discussion, extreme temperature analysis has been performed only at the country or state level. In the case of regional studies, it might differ depending upon the geographic location and history of climate at a particular place. With the deadly heat wave projected over densely populated agricultural regions like India, Im et al. [14] found that the bias in the historical simulation remains constant in the future projections, and impact assessments are biased by model deficiencies. So models have its limitations.

Akanbi et al. [1] found that besides economic growth, the climate change has a significant impact on human development. A study conducted by the National Commission for Rural Labour (1996) stated that the number of decadal interstate migration is about 11 million, as compared to the statewise migration for economic reasons was very high for Bihar (48.7\%) followed by Odisha (41.6\%). In the Odisha state, this large-scale migration has mainly contributed by the population in western Odisha, especially the districts of Kalahandi, Koraput and Balangir to neighboring Chhattisgarh. The non-profit organizations like Action Aid estimated that nearly 200,000 people migrated from Western Odisha to work in brick kilns of Andhra Pradesh during the year 2010 [42]. Further, the Migration Information and Resource Centre (MIRC) shows 150,000 people migrated from Bolangir district in 2009-2010. Hence, these are the principal motivation factors for choosing highly vulnerable 15 districts spread over western Odisha and eastern Chhattisgarh (Fig. 1). The aim of this study is to find temperature variability (heat wave) trends at a regional scale over the most vulnerable regions of the country. In the present context, this approach is more meaningful compared to the analysis at the country or state level as the districtwise or citywise temperature trends will provide a better knowledge about the scenario of that particular district and helps them to make better strategies for mitigation, adaptation and better preparedness. In Sect. 2, discussion regarding the data used and methodology followed for analysis is presented. Results are discussed in Sect. 3 with detailed explanations of the spatial and districtwise frequency and intensity trends of warm/cold days/nights. The research findings and its implications are highlighted in the conclusion Sect. 4.

\section{Data and methodology}

Fifteen districts ( 10 of western Odisha and 5 of neighboring Chhattisgarh), namely Jharsuguda, Sundargarh, Sambalpur, Deogarh, Angul, Subarnapur, Balangir, Bargarh, Kalahandi and Nuapada in Odisha and Raigarh, Janjgir Champa, Raipur, Mahasamund and Dhamtari in Chhattisgarh, are considered in this study (Fig. 1). For analyzing extreme temperature, we have considered daily maximum and minimum temperature at height of 2 meters from European Centre for Medium Range Weather Forecasting Interim Reanalysis (ERA-Interim) at 1430 and 0230 IST (Indian Standard Time) for three summer months (MAM) for 30 years (i.e., 1988-2017). Daily maximum (minimum) temperature valid for $1430 \mathrm{~h}(0230 \mathrm{~h})$ IST has been obtained from 0000 UTC (1200 UTC) initial conditions respectively. The grid resolution of ERA-Interim data considered in this study is at a horizontal resolution of $0.125^{\circ} \times 0.125^{\circ}(\sim 12 \mathrm{~km})$ [9]. The daily mean temperature is derived from an average of daily maximum and daily minimum temperature. In addition, the three year moving average analysis has been carried out for 30 years (1988-2017), here to mention that the moving average for 2016 are obtained by averaging 2016 and 2017 (last two years), and for the last year 2017, the values are kept as is (i.e. first value of moving average is the mean of the years 1988, 1989 and 1990 values, second one is mean of the years 1989, 1990, and 1991 values and so on.). We have followed the methodology described by Panda et al. [28] for calculating the warm days, cold days, warm nights and cold nights (Table 1). This is to mention that ERA-Interim high-resolution $(12 \mathrm{~km})$ gridded reanalysis data can provide better representation of the temperature at district scale and has an edge over station (point) or coarser resolution (i.e., $1 \mathrm{deg}$ ) gridded analysis of temperature from Indian Meteorological Department (IMD). 
Table 1 Method used for calculate terminologies

\begin{tabular}{ll}
\hline Terminology & Definition \\
\hline 1. Warm day & $>$ 90th percentile of daily maximum temperature \\
2. Warm night & $>$ 90th percentile of daily minimum temperature \\
3. Cold day & $<10$ th percentile of daily maximum temperature \\
4. Cold night & $<$ 10th percentile of daily minimum temperature \\
5. Frequency & $\begin{array}{l}\text { Number of sets }{ }^{\text {a }} \text { of consecutive days that follow } \\
\text { the above conditions }\end{array}$ \\
6. Intensity & The maximum number of days in a set
\end{tabular}

The 90th and 10th percentile values of the annual daily maximum temperature time series, estimated over the reference period (1988-2017)

aMentioned in "Appendix 1"

The following method is adopted for obtaining the values at the center of the respective districts. First, the particular district's latitude and longitude are obtained and considered as the center of a district (A). Now, one grid is added to all eight directions (i.e., A1-A8) from the respective center $(A)$ at a horizontal resolution of $\sim 12 \mathrm{~km}$ to make a square area of the district.

\begin{tabular}{|c|c|}
\hline -(A1) & •(A2) \\
\hline -(A4) & $\cdot(\mathrm{A})$ \\
\hline •(A6) & •(A7) \\
\hline
\end{tabular}

Through the aforementioned method, percentile values (Table 1) of the climatological period (1988-2017) of each district are obtained; further, this climatological percentile value is subtracted from the daily temperature value for all time period. After that, for a particular year out of 92 days (MAM), we extracted the sets of constitutive days which are above the climatological percentile value and these numbers of sets are considered as the frequency of that particular year, so that 30 years of trends can be obtained. Now the intensity is the maximum number of days out of the obtained sets for a particular year. After getting one value of intensity for each year, we got a trend of intensity for the whole studied years. (Figure 5 shows the districtwise frequency and intensity trends.)

In the same way, instead of the nine grids of the particular district, analysis is carried out for all grids falling inside the whole studied region (Fig. 1). So it ultimately presents the overall average trends of the frequency and intensity of whole studied region (Figs. 3 and 4). The quantitative definitions of warm/cold (day/night), their frequency and intensity are mentioned in Table 1. Spatial variation of frequency and intensity is the value of trends at each grid obtained by the same methodology (Figs. 6 and 7). For finding the heat wave cases, we have considered at least three consecutive days that avail the all four conditions for frequency and intensity (warm days, warm nights, cold days and cold nights). Those trends are plotted in Fig. 9.

\section{Results and discussions}

\subsection{Daily temperature trends}

Figure 2 shows the daily maximum, minimum and mean temperature of the entire region for MAM months covering 15 districts over the study region. It is noted that temperature increases at a rate of $0.006{ }^{\circ} \mathrm{C}, 0.012^{\circ} \mathrm{C}$ and $0.017^{\circ} \mathrm{C}$ per year, respectively (solid lines in Fig. 2). Interestingly, the rate of increase in the maximum temperature is not significant; however, the rate of increase in the minimum temperature has been doubled that of maximum temperature. Three-year moving average trends of daily maximum, minimum and mean temperature are $0.014^{\circ} \mathrm{C}$, $0.017^{\circ} \mathrm{C}$ and $0.020^{\circ} \mathrm{C}$ per year (dotted lines in Fig. 2). Our result is in agreement with those obtained by Gouda et al. [12], where using IMD data, they have noted that the daily maximum temperature has a strong positive trend $\left(0.71^{\circ} \mathrm{C}\right.$ /year) during the $1989-1998$ over Odisha. Further, the study also noted that in the recent period (2009-2015) the trend of maximum temperature over Odisha has been increasing at a rate of $0.41^{\circ} \mathrm{C} /$ year.

\subsection{Frequency and intensity trends}

In Figs. 3 and 4, climatological trends follow an increasing rate of warm night frequency (0.0044 times/year, i.e., 0.0044 number of sets (Table 1) increasing per year), while warm day, cold day and night frequencies have indicated decreasing trends. At the same time, the intensity of warm night has increased at a rate of 0.074 days/year (i.e., in a particular set 0.074 number of days increases per year). Warm nights play an important role in temperature extremes over the study region, often leading to health hazards [22]. Besides, cold night frequency and intensity have also shown a decreasing rate, i.e., -0.048 times/year and -0.07 days/year, respectively, over the study region. Venkatesh [37] has found that, over the Indian region, the heat wave frequency will increase by 39 events in the next 30 years compared to heat wave frequency between 1971 and 2000 and this increase is projected to be as high as 18-30 events by the final quarter of the twenty-first century; our findings also support this increasing trend. 


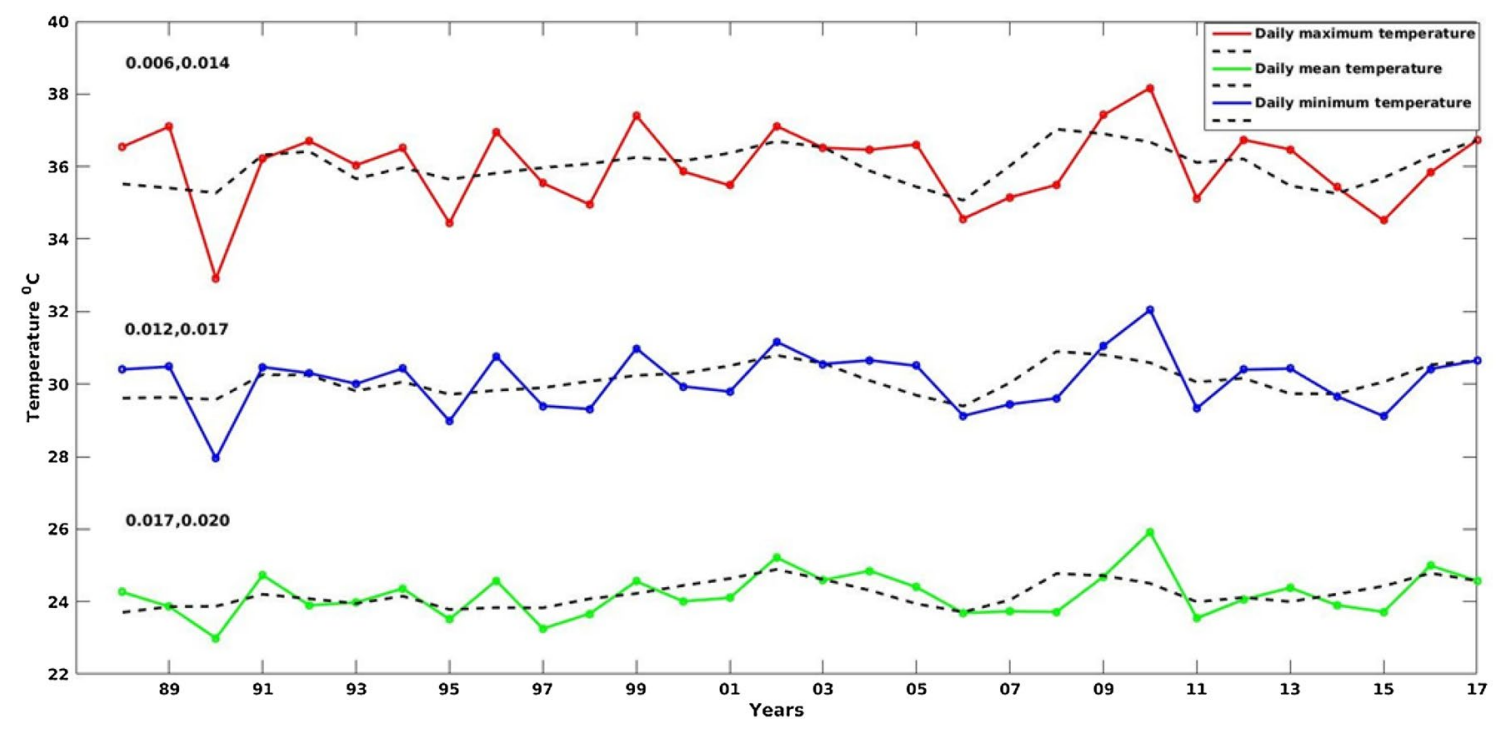

Fig. 2 Trend of the temperature of daily maximum (red), daily minimum (blue) and daily mean (green) for the month of MAM of the year 1988-2017. The dotted line indicates a moving average of 3 years. Two values above each graph show the slope of the colored line (left) and the dotted line (right), respectively
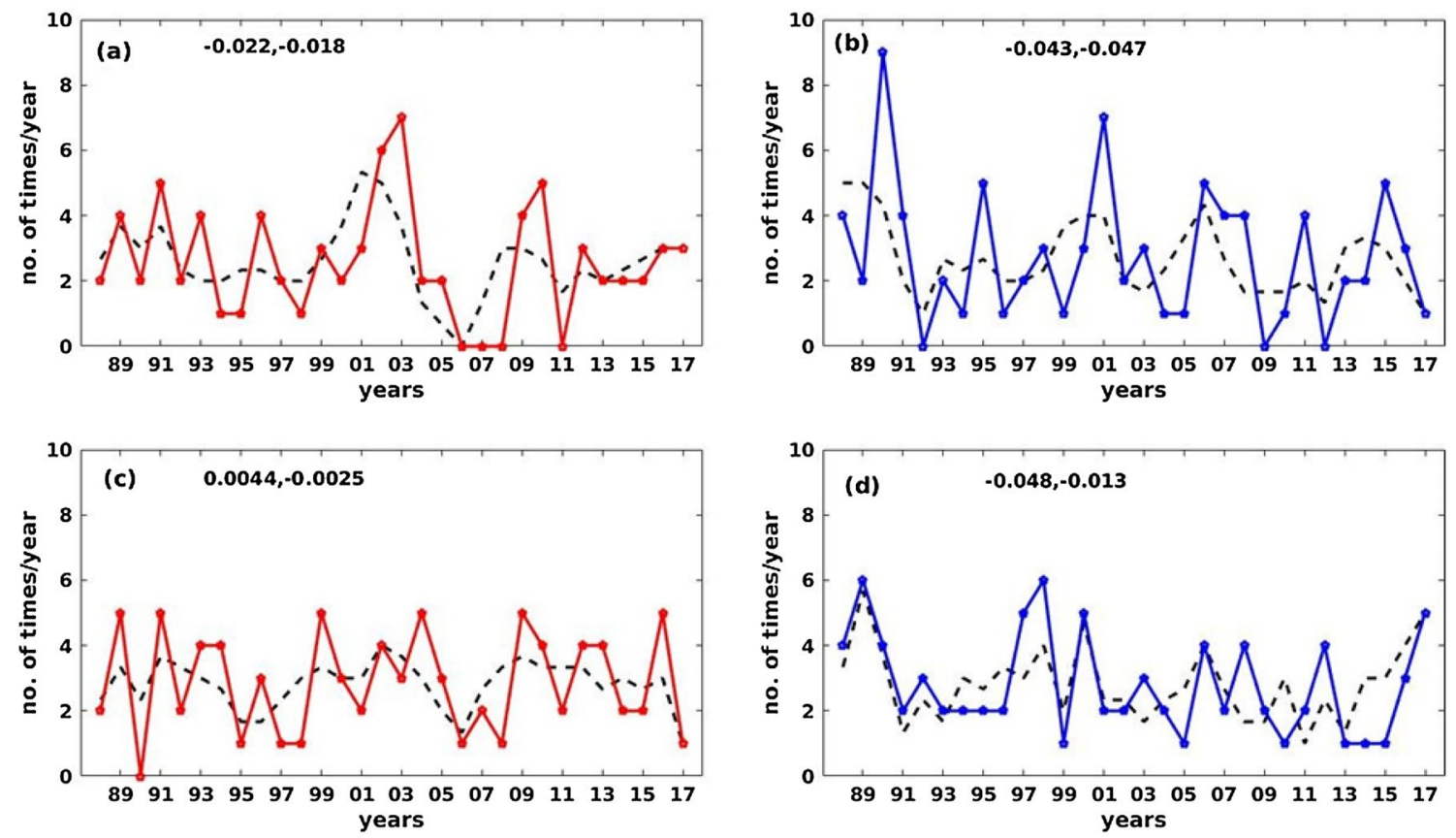

Fig. 3 Frequency trends: a warm days, b cold days, c warm nights, $\mathbf{d}$ cold nights. The dotted line shows a 3-year moving average. Two values above each graph show the slope of the colored line (left) and dotted line (right)

\subsection{Districtwise frequency and intensity trends}

Figure 5 shows that most of the districts show an increasing trend of the warm night frequency with Raigarh (Chhattisgarh) having the highest increasing trend (0.13 times/year) followed by Odisha districts, namely
Sundargarh, Jharsuguda and Sambalpur. Interestingly, warm day frequency and intensity have shown the negative trends in the majority of these districts ( 10 nos.) for time period considered. The trend pattern of these 10 districts reflects the representation of the study area. Simultaneously, the frequency of cold days and night for all 

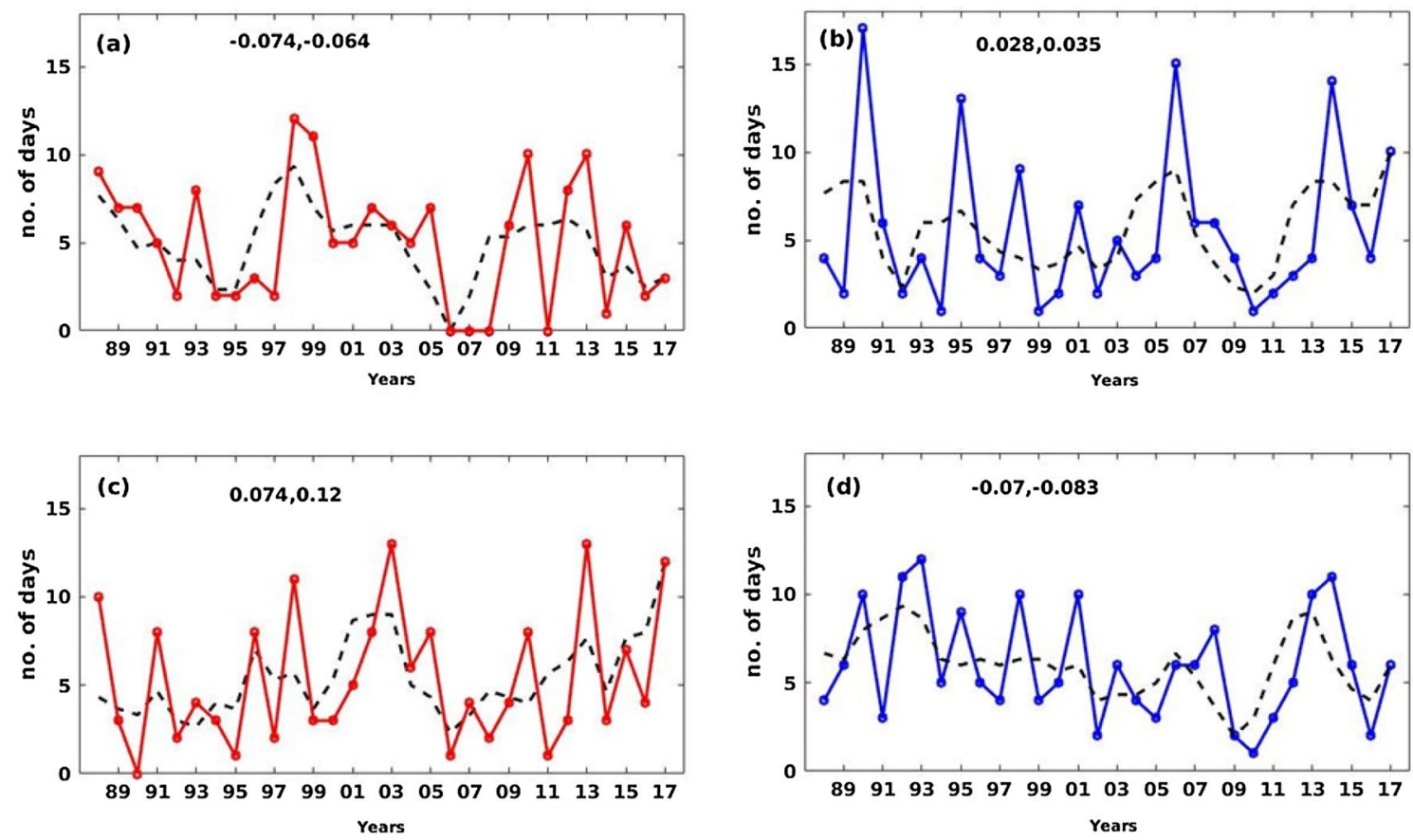

Fig. 4 Intensity trends: a warm days, $\mathbf{b}$ cold days, $\mathbf{c}$ warm nights, $\mathbf{d}$ cold nights. The dotted line shows a 3-year moving average. Two values above each graph show the slope of the colored line (left) and dotted line (right)
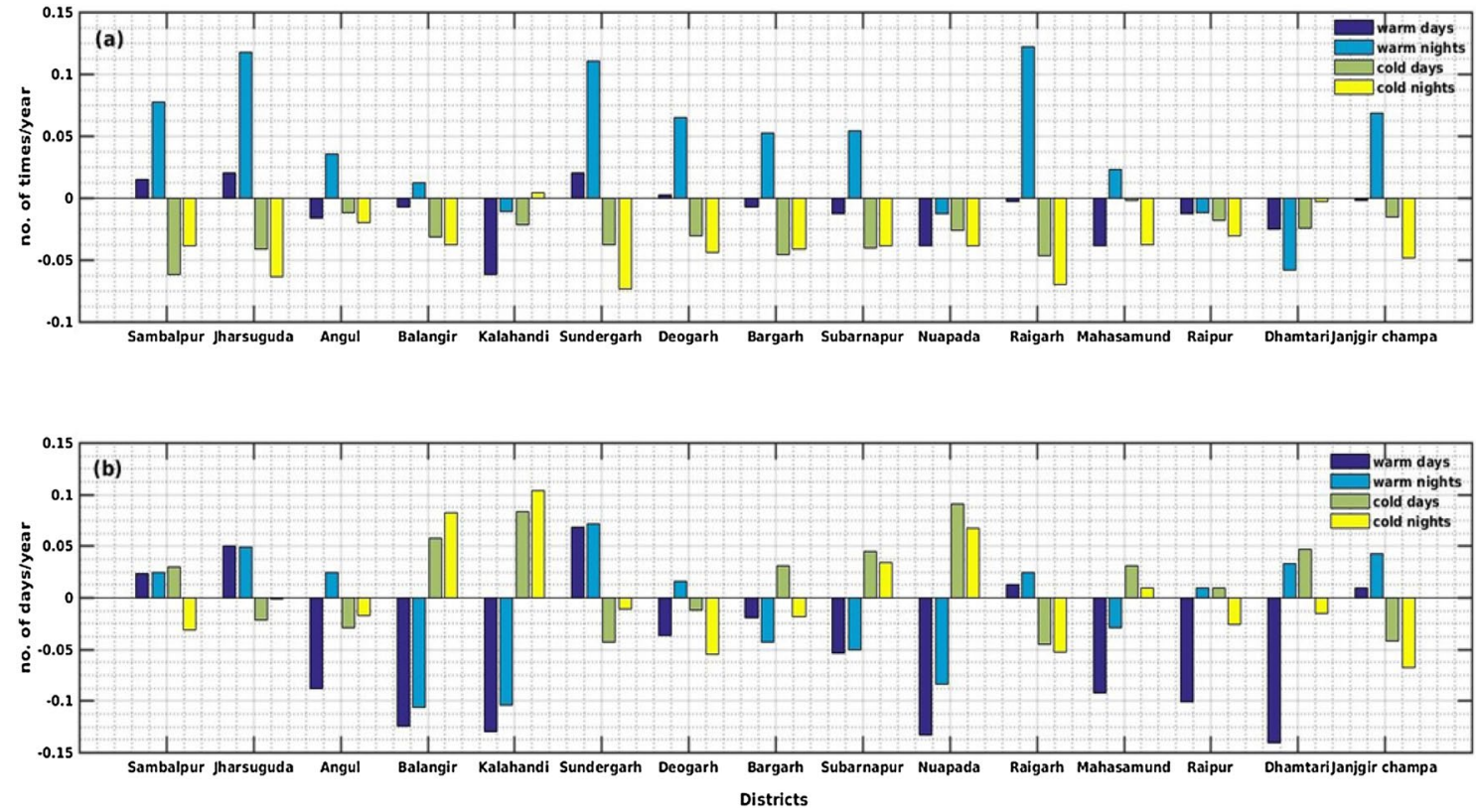

Fig. 5 Districtwise a frequency trend, $\mathbf{b}$ intensity trend over the time period of 1988-2017

studied districts follows a decreasing trend. Highest warm day intensity was felt at Sundargarh (nearly 0.07 days/year) followed by Jharsuguda, Sambalpur, Raigarh and Janjgir Champa; these districts also face the positive consecutive warm night intensity.

\subsection{Spatial variation of frequency and intensity trends}

The 90th percentile of daily maximum temperature is concentrated over the west and central parts of the study 

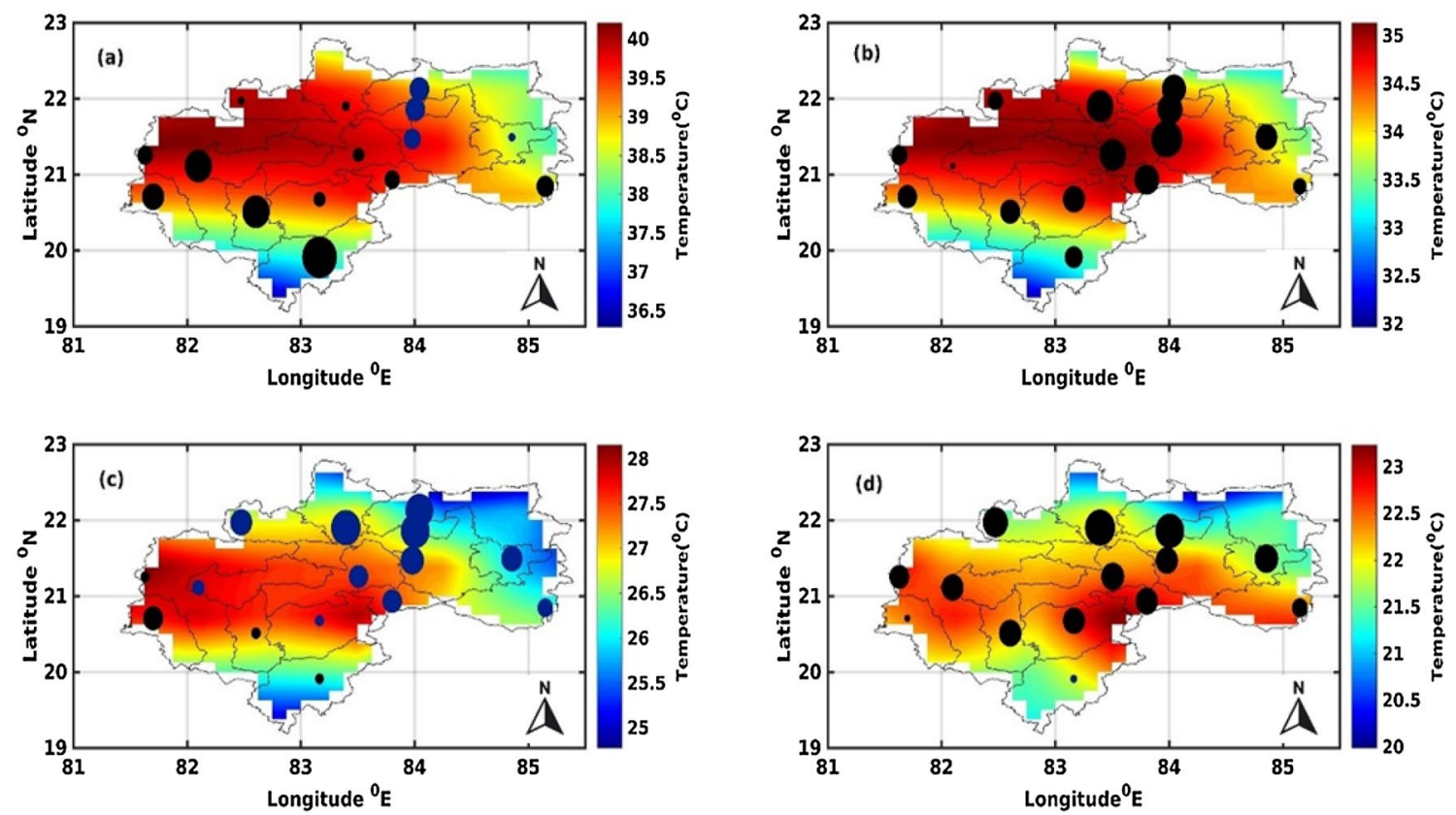

Fig. 6 Frequency trend variation positive (blue) and negative (black) of the a warm days, $\mathbf{b}$ cold days, $\mathbf{c}$ warm nights, $\mathbf{d}$ cold nights; the color shows the respective percentile temperature values. Size of the circle indicates the quantitative value of the trend
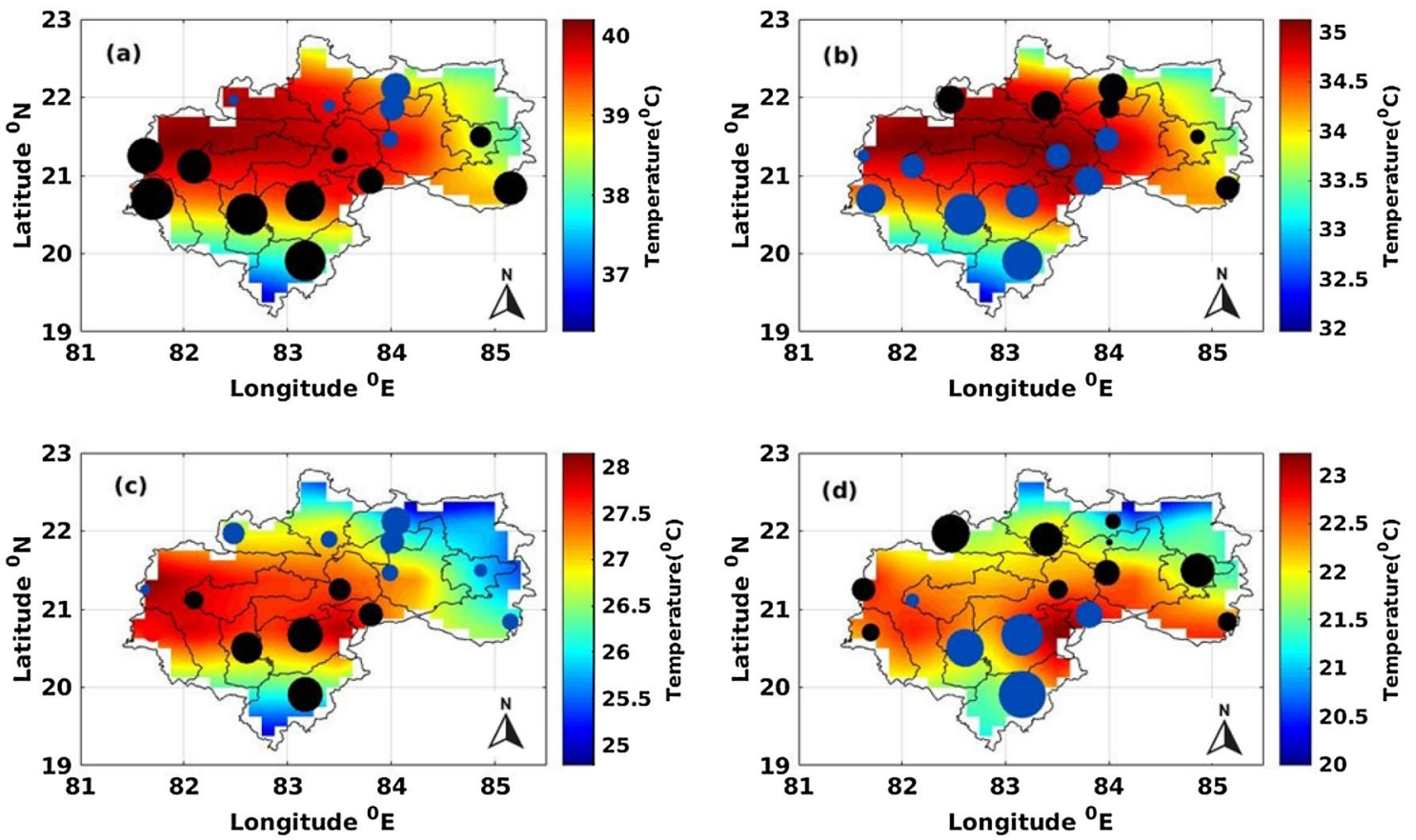

Fig. 7 Intensity trend variation positive (blue) and negative (black) of the a warm days, $\mathbf{b}$ cold days, $\mathbf{c}$ warm nights, $\mathbf{d}$ cold nights; the color shows the respective percentile temperature values. Size of the circle indicates the quantitative value of the trend

region (Fig. 6a) and ten out of fifteen districts falling in those regions experienced negative trends of warm day frequency and other districts face little bit positive trends (northeastern part of the region). Over the central part of the study region, cold day frequency indicated highest decreasing trends (i.e., for Sambalpur cold day frequency trends nearly -0.07 times/year) (Fig. 6b). Northern districts (Jharsuguda, Sundargarh, Raigarh and Janjgir Champa) of 
study region face both positive warm day intensity and negative cold day intensity (Fig. 7a, b). Warm night frequency positive trends (ranging from 0.01 to 0.13 times/ year) identified toward the northeastern part of the study region though the 90th percentile of daily minimum temperature concentrated over the western side of the region (Fig. 6C). All districts except Kalahandi face negative cold night frequency trends (ranges from -0.005 to -0.07 times/year). The frequency of warm days found to be increasing over northern districts of the study region (Jharsuguda, Sundargarh, Sambalpur and Deogarh) (Fig. 6a). Districts below $21^{\circ} \mathrm{N}$ (i.e., Nuapada, Kalahandi, Balangir and Subarnapur) of the study region have shown highly negative trends of warm day intensity (ranges from -0.05 to -0.14 days/year) and positive trends of cold night intensity (ranges from 0.04 to 0.1 days/year) (Fig. 7a, d). It is evident that the six northern districts (above $21^{\circ} \mathrm{N}$ ) are having an increase (decrease) in trends of the warm night (cold night) intensity (Fig. 7c, d). Figure 8 shows the warm night trends highest in Sundargarh ( 0.32 days per year) followed by Raigarh, Jharsuguda, Janjgir Champa and Sambalpur. Sundargarh is also highest in the warm day trend ( 0.2 days/year), followed by Jharsuguda ( 0.16 days/year), Sambalpur (0.06 days/year), Raigarh (0.06 days/year) and Janjgir Champa (0.4 days/year). Total cold night trends in most of the districts show the negative value, highest in Raigarh ( -0.24 days/year).

\subsection{Consecutive 3-day trends}

Meehl and Tebaldi [19] found that three-day average maximum temperature estimated from the daily maximum temperature data was considered as an alternative heatwave measure because the mean of three consecutive warmest days obtained from observations and the model are in agreement. Figure 9 explains the trends of consecutive 3 days for each district that gives a better idea about the heat wave conditions. Descending order of the districts facing positive trends of the warm nights are Sundargarh ( 0.05 days/year), Janjgir Champa ( 0.04 days/year), Raigarh ( 0.035 days/year), Jharsuguda ( 0.025 days/ year) and Sambalpur ( 0.02 days/year). Except for Nuapada, all the districts have negative trends for consecutive three cold nights. At the same time, the cold night intensity in Nuapada increases at a rate of $\sim 0.03$ days/ year (Fig. 9). In Sundargarh, Jharsuguda and Sambalpur, warm night frequency (intensity) shows increasing trends of $\sim 0.12$ times/year ( $~ 0.07$ days/year), $\sim 0.13$ times/year ( $\sim 0.05$ days/year) and $\sim 0.075$ times/year ( 0.02 days/ year), respectively (Fig. 5).

\subsection{Climate Implications}

Results of this study have serious concern over the human comfort, productivity and health which directly impact on country's economy. International Labour Organisation (ILO) released its report 'Working on a Warmer Planet: The Impact of Heat Stress on Labour Productivity and Decent Work' [15], which said that by 2030 , India is projected to lose $5.8 \%$ of working hours and a productivity loss equivalent to 34 million full-time jobs, due to global warming, particularly impacting agricultural and construction sectors. The human resource has to acquire the knowledge about climate change to adopt individual behavior change and performance enhancement so as to gear up its efficiency and effectiveness [3]. In nutshell, this analysis may implicate the person's perception and seriousness toward the climate change and problem associated with it. These two factors are very useful for adopting strategies [30].

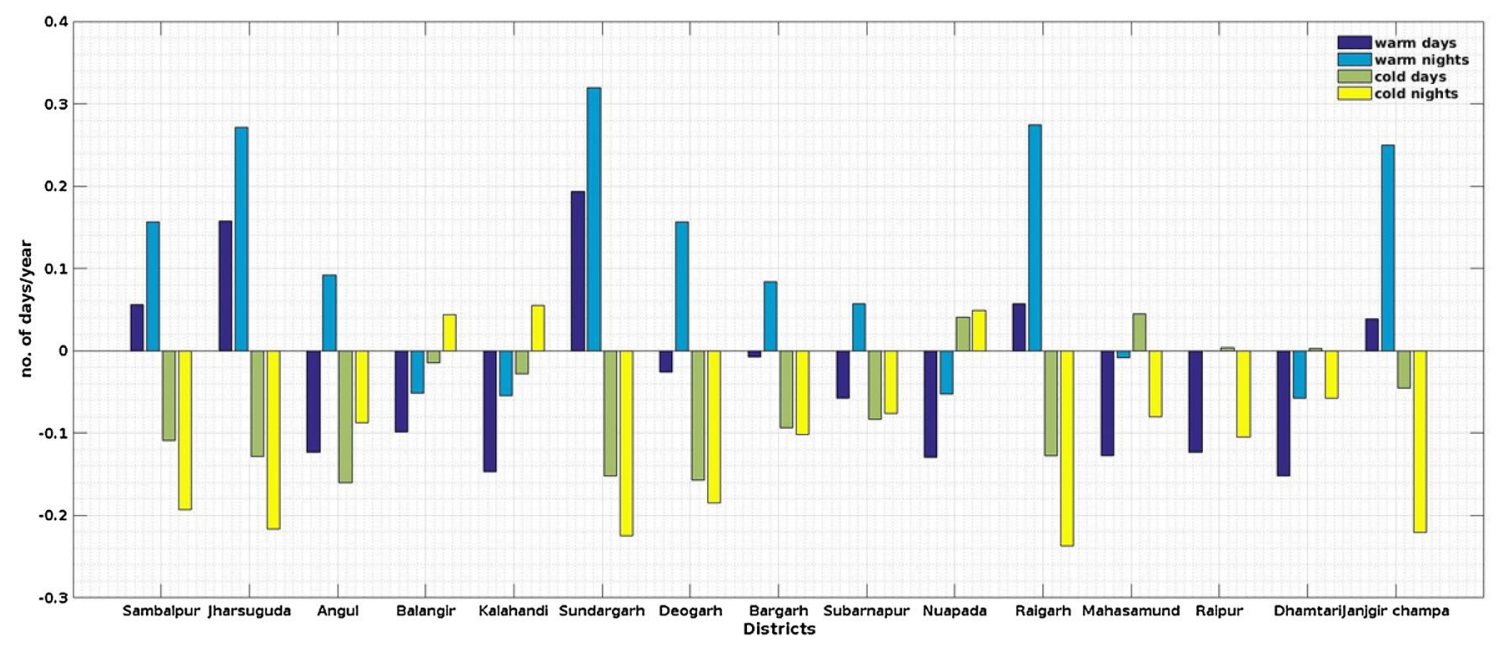

Fig. 8 Total number of warm/cold day/night trend over period 1988-2017 (MAM) 


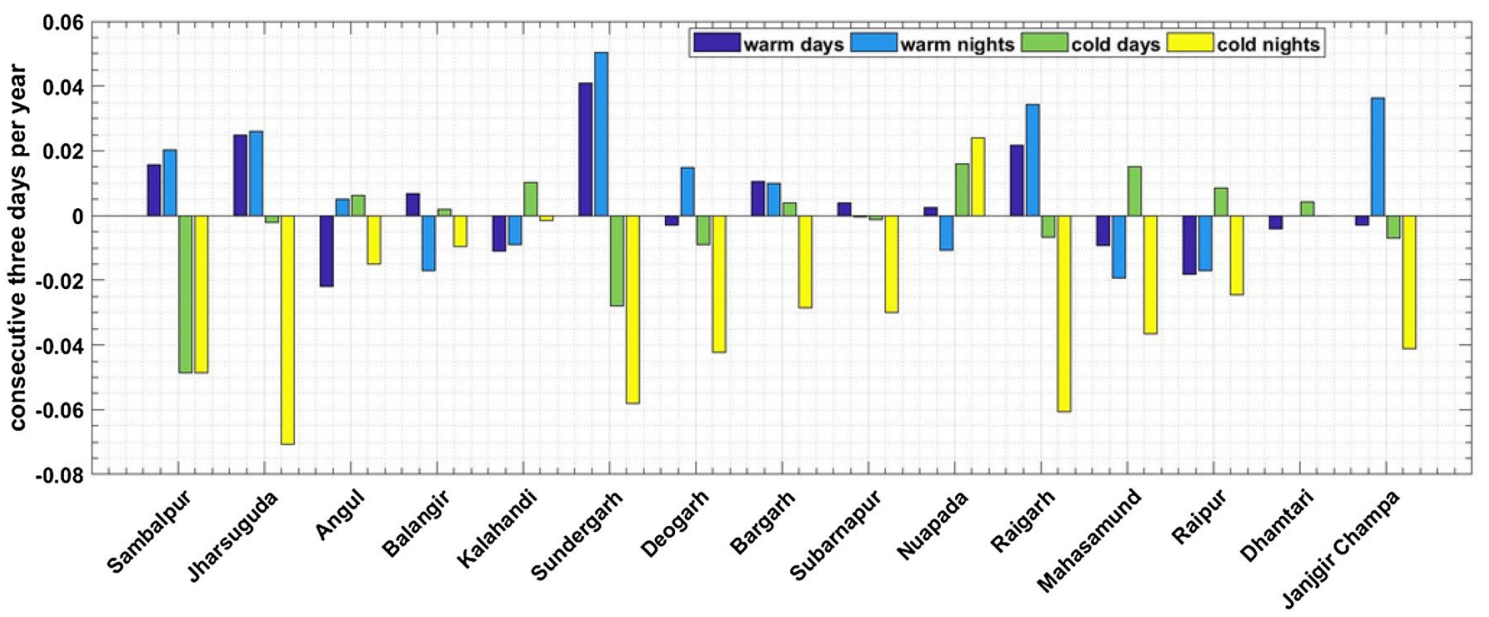

Fig. 9 Consecutive three-day trends of each district

\section{Conclusions}

Results suggest that the frequency and intensity of warm nights have increased significantly, while the frequency of cold night and its intensity has decreased during the time period (1988-2017). Raigarh in Chhattisgarh has the highest increasing trend of warm night frequency (0.13 times/year) followed by Jharsuguda, Sundargarh and Sambalpur (Odisha districts). Further, it is noted that Sundargarh district has the highest increasing trend of warm day and warm night intensity ( 0.065 and 0.07 days/ year), respectively, followed by Jharsuguda, Sambalpur, Raigarh and Janjgir Champa. Except slight positive value of cold night frequency in Kalahandi, all districts shows the negative trends for cold night frequency; in addition, frequency of cold days for all 15 districts showed a decreasing trend. The frequency of cold days and nights in most of the districts is indicating a decreasing trend. Cold day (night) intensity shows highest decreasing trends of -0.045 days/year ( -0.065 days/year) over Raigarh (Janjgir Champa) of Chhattisgarh. Though the 90th percentile of daily minimum temperature concentrated over the western side of the region, it appears that increasing trends of warm night frequency are shifting toward the northeastern part of the study region. Sundargarh has the highest trends of warm days ( 0.2 days/year) and warm nights ( 0.32 days/year) among all 15 districts. In a nutshell, we found that frequency of warm nights has increased compared to warm days that might lead to an adverse impact on health and livelihood conditions of the local population. After identifying the variation and changes of extremes temperature of the studied districts, we may get the generalized idea about the future trends; thus, in the context of climate change impact, adaptation, mitigation and equity in resource availability have become an important issue to be incorporated in socioeconomic policy planning. This study has demonstrated that there is a growing concern about the temperature variability in western Odisha districts; hence, administrators should take this information into view while formulating policies to safeguard socioeconomically vulnerable section of the society in these regions. Further, they should develop strategies to mitigate the impact in terms of human health, mortality and migration and devise customized innovating practices to address future challenges due to climate change. The study recommends for future research and policy advocacy for robust customized solutions and innovative strategies for this region, particularly for vulnerable western Odisha districts.

Acknowledgements The authors are grateful to the Indian Institute of Technology Bhubaneswar for providing necessary support in terms of fellowship and infrastructure to carry out this research work. We are also grateful to European Centre for Medium Range Weather Forecasting (ECMWF) for providing reanalysis data free of cost. The MATLAB software has been extensively used to carry out the analysis and visualization for this paper.

\section{Compliance with ethical standards}

Conflict of interest On behalf of all authors, the corresponding author states that there is no conflict of interest. 


\section{Appendix 1}

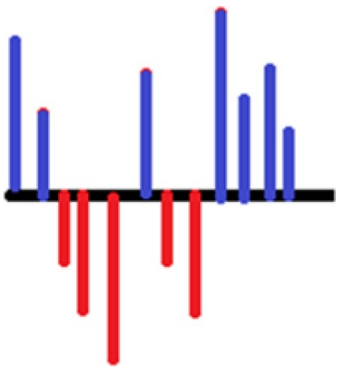

- The black line is the threshold value (percentile value).

- Blue (red) line is a positive (negative) anomaly from the percentile value of each day. (Here 12 days only is taken for example, but the real data analysis is carried out for 92 days/year.)

- Three sets are above the percentile values (blue), so frequency is three.

- Out of three sets, the highest number of days is four, so the intensity is counted as four.

- Example applicable to warm days and warm nights only.

- For cold days and cold nights, the calculation is based on red-colored line.

\section{References}

1. Akanbi BE, Adagunodo M, Satopea BF (2014) Climate change, human development and economic growth in Nigeria. Int J Humanit Soc Sci 4:222-228

2. Akhtar R (2007) Climate change and health and heat wave mortality in India. Glob Environ Res Engl Ed 11:51

3. Balanagarajan K, Gajapathy V (2018) Climate changes and its impact on employee productivity. Int J Appl Eng Res 13:27-29

4. Burrows K, Kinney P (2016) Exploring the climate change, migration and conflict nexus. Int J Environ Res Public Health 13(4):443

5. Chaudhuri G, Mishra NB (2016) Spatio-temporal dynamics of land cover and land surface temperature in Ganges-Brahmaputra delta: a comparative analysis between India and Bangladesh. Appl Geogr 68:68-83

6. Christidis N, Jones GS, Stott PA (2015) Dramatically increasing chance of extremely hot summers since the 2003 European heatwave. Nat Clim Change 5(1):46

7. Dash SK, Mamgain A (2011) Changes in the frequency of different categories of temperature extremes in India. J Appl Meteorol Climtol 50(9):1842-1858

8. De US, Dube RK, Rao GP (2005) Extreme weather events over India in the last 100 years. J Indian Geophys Union 9:173-187

9. Dee DP, Uppala SM, Simmons A, Berrisford P, Poli P, Kobayashi $S$, Andrae U, Balmaseda MA, Balsamo G, Bauer DP, Bechtold $P$ (2011) The ERA-interim reanalysis: configuration and performance of the data assimilation system. Q J R Meteorol Soc 137(656):553-597

SN Applied Sciences
10. Dunne JP, Stouffer RJ, John JG (2013) Reductions in labour capacity from heat stress under climate warming. Nat Clim Change 3(6):563

11. Gaffen DJ, Ross RJ (1998) Increased summertime heat stress in the US. Nature 396(6711):529

12. Gouda KC, Sahoo SK, Samantray P, Himesh S (2017) Simulation of extreme temperature over Odisha during May 2015. Weather Clim Extrem 17:17-28

13. He BJ, Zhao ZQ, Shen LD, Wang HB, Li L (2019) An approach to examining performances of cool/hot sources in mitigating/ enhancing land surface temperature under different temperature backgrounds based on Landsat 8 image. Sustain Cities Soc 44:416-427

14. Im ES, Pal JS, Eltahir EA (2017) Deadly heat waves projected in the densely populated agricultural regions of South Asia. Sci Adv 3(8):603322

15. International Labour Organisation (ILO) (2019) Working on a warmer planet: the effect of heat stress on productivity and decent work. https://www.ilo.org/wcmsp5/groups/publi c/-dgreports/—dcomm/—publ/documents/publication/ wcms_711919.pdf. Accessed 15 July 2019

16. Jena PP (2017) Impact of climate change on Odisha, economic development-A comparative analysis. J Humanit Soc Sci 22:21-25

17. Kosal Discussion and Development Forum, Jharsuguda-Brajrajnagar-Belpahar area: the industrial belt of western Odisha, www.kddfonline.com. Accessed 11 May 2012; http://wp.me/ pFC4h-1 bv Accessed 28 Feb 2019

18. Matthews TK, Wilby RL, Murphy C (2017) Communicating the deadly consequences of global warming for human heat stress. Proc Natl Acad Sci 114(15):3861-3866

19. Meehl GA, Tebaldi C (2004) More intense, more frequent, and longer lasting heat waves in the 21 st century. Science 305(5686):994-997

20. Meehl GA, Zwiers F, Evans J, Knutson T, Mearns L, Whetton P (2000) Trends in extreme weather and climate events: issues related to modeling extremes in projections of future climate change. Bull Am Meteorol Soc 81(3):427-436

21. Mishra V, Ganguly AR, Nijssen B, Lettenmaier DP (2015) Changes in observed climate extremes in global urban areas. Environ Res Lett 10(2):024005

22. Mishra V, Mukherjee S, Kumar R, Stone DA (2017) Heat wave exposure in India in current, $1.5^{\circ} \mathrm{C}$, and $2.0^{\circ} \mathrm{C}$ worlds. Environ Res Lett 12(12):124012

23. Murari KK, Ghosh S, Patwardhan A, Daly E, Salvi K (2015) Intensification of future severe heat waves in India and their effect on heat stress and mortality. Reg Environ Change 15(4):569-579

24. Odisha State Disaster Management Authority (2018) Heat action plan for Odisha. http://www.osdma.org/Download/ heat-wave-action-plan.pdf. Accessed 30 Apr 2019

25. Oldenborgh GJV, Philip S, Kew S, Weele MV, Uhe P, Otto F, Singh R, Pai I, Cullen H, AchutaRao K (2018) Extreme heat in India and anthropogenic climate change. Nat Hazards Earth Syst Sci 18:365-381

26. Pai DS, Thapliyal V, Kokate PD (2004) Decadal variation in the heat and cold waves over India during 1971-2000. Mausam 55:281-292

27. Pai DS, Nair SA, Ramanathan AN (2013) Long term climatology and trends of heat waves over India during the recent 50 years (1961-2010). Mausam 64:585-604

28. Panda DK, Mishra A, Kumar A, Mandal KG, Thakur AK, Srivastava RC (2014) Spatiotemporal patterns in the mean and extreme temperature indices of India, 1971-2005. Int J Climatol 34:3585-3603 
29. Panda DK, Aghakouchak A, Ambast SK (2017) Increasing heat waves and warm spells in India, observed from a multiaspect framework. J Geophys Res Atmos 122:3837-3858

30. Patel SK (2016) Climate change and climate-induced disasters in Odisha, Eastern India: impacts, adaptation and future policy implications. Int J Humanit Soc Sci Invent 5:60-63

31. Pattanayak A, Kavi Kumar KS (2014) Weather sensivity of rice yield: evidence from India. Clim Chang Econ 05(04):1450011. https://doi.org/10.1142/S2010007814500110

32. Peng S, Huang J, Sheehy JE, Laza RC, Visperas RM, Zhong X, Centeno GS, Khush GS, Cassman KG (2004) Rice yields decline with higher night temperature from global warming. Proc Natl Acad Sci 101:9971-9975

33. Rahmstorf S, Coumou D (2011) Increase of extreme events in a warming world. Proc Natl Acad Sci 108(44):17905-17909

34. Rohini P, Rajeevan M, Srivastava AK (2016) On the variability and increasing trends of heat waves over India. Sci Rep 6:26153

35. Ross RS, Krishnamurti TN, Pattnaik S, Pai DS (2018) Decadal surface temperature trends in India based on a new high-resolution data set. Sci Rep 8(1):7452

36. Sekertekin A, Kutoglu SH, Kaya S (2016) Evaluation of spatiotemporal variability in land surface temperature: a case study of Zonguldak, Turkey. Environ Monit Assess 188:30

37. Shreeshan V(2017) Intensity, extent and duration of severe heat waves to increase dramatically. Down to earth, 17 Oct 2017

38. Smith SC, Das S (2012) Awareness is an adaptation strategy for reducing mortality from heat waves: evidence from a disaster risk management program in India. Institute for International Economics Policy, New York (no. 2012-6)

39. Smith KR, Woodward A, Campbell-Lendrum D, Chadee DD, Honda Y, Liu Q, Olwoch JM, Revich B, Sauerborn R (2014) Human health: impacts, adaptation, and co-benefits climate change 2014: impacts, adaptation, and vulnerability. Part A: global and sectoral aspects; contribution of working group II to the fifth assessment report of the intergovernmental panel on climate change. Cambridge University Press, Cambridge, pp 709-754

40. Srivastava AK, Singh GP, Singh OP, Choudhary UK (2015) Recent variability and trends in temperatures over India. Vayumandal 40:161-181

41. Sun $Y$, Zhang $X$, Zwiers FW, Song $L$, Wan $H$, Hu T, Yin $H$, Ren $G$ (2014) Rapid increase in the risk of extreme summer heat in Eastern China. Nat Clim Change 4(12):1082

42. Thompson K, Mohammed A, Sundaray S, Akerkar S, Daniel $U$ (2005) Bolangir to Hyderabad and the politics of poverty; ActionAid. http://www.actionaid.org/sites/files/actionaid/bolan gir_to_hyderabad.pdf. Accessed 1 Dec 2005

Publisher's Note Springer Nature remains neutral with regard to jurisdictional claims in published maps and institutional affiliations. 